\title{
Simultaneous determination of selected anti-nutritional components in Asiatic plants using ion chromatography
}

\author{
A. Filipiak-Szok ${ }^{1}$ M. Kurzawa $^{1} \cdot$ E. Szłyk ${ }^{1}$
}

Received: 22 September 2015 / Revised: 21 January 2016 / Accepted: 6 February 2016 / Published online: 25 February 2016

(C) The Author(s) 2016. This article is published with open access at Springerlink.com

\begin{abstract}
Anti-nutritional components such as: oxalates, thiocyanates and phytic acid were determined in 20 plants samples originated from Traditional Chinese Medicine and Ayurveda (e.g., Andrographis paniculata, Angelica sinensis, Emblica officinalis, Withania somnifera, Polygonum multiflorum, Bacopa monnieri, Pueraria lobata, Cola accuminata, Curcuma longa, Ocimum sanctum, Mucuna pruriens, Garcinia cambogia, Panax ginseng, Bupleurum sinensis, Salviae miltiorrhizae, Schisandra sinensis, Terminalia arjuna). Extraction and analysis procedures for these anti-nutritional components determination were modified and optimized. Water-soluble oxalates, thiocyanates and phytic acid were simultaneously determined by new procedure with ion chromatography method, resulting in analyzed samples: $0.38-145.39 \mathrm{mg} 100 \mathrm{~g}^{-1}$ dry mass (d.m.) for oxalates, $0.94-34.34 \mathrm{mg} 100 \mathrm{~g}^{-1}$ d.m. for thiocyanates, whereas $0.42-16.13 \mathrm{mg} 100 \mathrm{~g}^{-1}$ d.m. for phytic acid. The highest of the total content of anti-nutritional components was observed for the $O$. sanctum, but the lowest for $C$. longa. Moreover, oxalates and phytic acid were determined by titration, whereas thiocyanates by spectrophotometric method.
\end{abstract}

Keywords Plants - Traditional medicine - Oxalates . Phytic acid · Thiocyanates

A. Filipiak-Szok

ania_fsz@chem.umk.pl

1 Faculty of Chemistry, Nicolaus Copernicus University in Toruń, Gagarin 7 St., 87-100 Toruń, Poland

\section{Introduction}

Traditional Chinese Medicine and Ayurveda are using a number of plants for treatment of different diseases. It is well known that plant materials contain numerous ingredients revealing health promoting action (e.g., polyphenols, flavonoids, phenolic acids, anthocyanins, vitamins, microand macroelements). However, plants can also contain toxic substance or components that can interfere with minerals or nutrients consumed daily. Substances that impede or completely prevent the use of nutrients in foods, and also have a negative impact on human body are called antinutritional (e.g., phytic acid, oxalic acid, glucosinolates and thiocyanates, tannins, phosphates and accidentally introduced contaminants-pesticides) [1].

Oxalic acid is present in plants along with the biosynthetic substrates such as: ascorbic acid, tryptophan, hydroxyproline, serine and ethylamine. Oxalic acid and its insoluble salts with di- and trivalent metal ions can be harmful for the human health, because of their anti-nutritional action against food components and toxicity. It should be emphasized that the anti-nutritive effect of oxalates depends not only on the absolute content in food, but also the relative ratio of elements which are able to form insoluble salts, especially: $\mathrm{Mg}, \mathrm{Ca}, \mathrm{Fe}$ $[2,3]$. Research revealed that the daily intake of oxalates is much higher than permitted values, e.g., $40-50 \mathrm{mg} /$ day [2]. Moreover, oxalates absorption from food varied, e.g., from spinach, $4.5-6.2 \%$ for spinach and $1.9-4.7 \%$ for tea samples up to $9 \%$ [4]. It should be noted that oxalates from the exogenous sources if, even administered in small amounts, can cause hyperoxaluria, nephrolithiasis, renal failure, cardiomyopathy and cardiac conductivity disorders [2,3].

Thiocyanates occur both in plant tissues and animals, as well as in body fluids such as blood, saliva or urine. In plants, they are components of compounds called 
glucosinolates [5]. These anions in our body are involved in many biological and medical functions, e.g., in cell growth stimulation, in immune response and in phagocytosis. Furthermore, in a different way the functioning of the thyroid gland is affected by $\mathrm{SCN}^{-}$, depending on the concentration. At low concentrations, it can stimulate the operation, while pathologically elevated concentrations inhibit the accumulation of iodine in the thyroid gland [5]. Thiocyanates concentration in the body is essentially dependent on the applied diet. The negative effect of thiocyanates can be observed in persons on the diet rich in cruciferous plants and low in iodide ions simultaneously.

Phytic acid occurs naturally and can be found mainly in grains, legumes, nuts and seeds oil plants [6]. Anti-nutritive activity of phytates is mainly linked to their strong chelating properties. Phytates exhibit a high affinity toward important for human body micro- and macroelements. They influence functioning of the enzymes necessary for proper digestion and also bind proteins reducing their availability for organism [6]. In conclusion, it can be suggested that anti-nutritional substances affect the organism mineral homeostasis, resulting in deficiencies of metal ions essential for the proper functioning of the human organism.

Oxalates can be determined by various analytical methods, such as: $\mathrm{KMnO}_{4}$ titration [7], high-performance liquid chromatography (HPLC) with UV detection [8], HPLC with enzymatic detection [9], capillary electrophoresis [10], ion chromatography [11], chemiluminescence [12] and spectrophotometry NIR [13].

Spectrophotometric determination of thiocyanates was described in numerous papers [14, 15], whereas spectrofluorimetric method was studied by [16]. Ion-selective membrane electrode was used by [17]. Separation techniques such as: ion pair chromatography [18], capillary electrophoresis [19] or micellar electrokinetic capillary chromatography [20], were applied as well.

Determination of phytic acid in food was studied by volumetric titration [21, 22], capillary isotachophoresis [23] and ion-exchange liquid chromatography [24]. Spectrophotometric [25] and synchronous fluorescence [25] were reported as well. Although various analytical techniques were applied for determination of these three analytes, there are no reports on their determination in the studied plants.

Increasing consumption of dietary supplements, herbs and herbal teas in Poland, advertised as health promoted or prophylactic compositions (e.g., due to the presence of antioxidants), is evident. However, besides the prohealthy components in the plant materials and supplements, the antinutritional and negative health effects compounds are also present. They may increase the risk of a number of ailments associated with impaired balance of macronutrients and trace elements in the human body, described above. Plants used in Traditional Chinese Medicine and Ayurveda (e.g., Andrographis paniculata, Angelica sinensis (Dong quai), Emblica officinalis (Amla, Amalaki), Withania somnifera (Ashwagandha), Polygonum multiflorum (FoTi), Bacopa monnieri (Brahmi), Pueraria lobata (Kudzu root), Cola accuminata, Curcuma longa, Ocimum sanctum, Mucuna pruriens, Garcinia cambogia, Panax ginseng, Bupleurum sinensis, Salviae miltiorrhizae, Schisandra sinensis, Terminalia arjuna) have been studied. These plants are also used in preparation of dietary supplements, herbal teas or used as pure herbs.

Considering to the above properties and because of in the literature there is a lack of information on the studied substances content in plants, it is necessary to determine the concentration level of oxalates, thiocyanates and phytates in the popular medicinal plants, herbs and dietary supplements. For this purpose, proposed, new and optimized methodology [ion chromatography (IC) technique] for simultaneous determination of studied anti-nutritional compounds has been applied. Additionally, oxalates and phytic acid were determined by titration, whereas thiocyanates by spectrophotometric method.

\section{Materials and methods}

\section{Materials}

Ashwagandha, Amla, A. paniculata (coded APl-S and APr$\mathrm{S}$, where 1-leaves, r-roots and S-standard, because these samples were supplied from Standard, Poland), A. sinensis (AS), Bacopa monnieri (BM), Bupleurum sinensis (BS), Cola accuminata (CA), Curcuma longa (CL), FoTi, Garcinia cambogia (GC), Mucuna pruriens (MP), Ocimum sanctum (OS), Panax ginseng (PG), Pueraria lobata (PL), Salvia miltiorrhizae (SM), Schisandra sinensis (SSS), Terminalia arjuna (TA) were purchased from Standard (Lublin, Poland), while A. paniculata APl-B was supplied from Biofaktor (Gorzów Wlkp., Poland) and Schisandra sinensis coded as SS-FL from FENG-LUKA (Goleniów, Polska).Oxalic acid $\left(\mathrm{H}_{2} \mathrm{C}_{2} \mathrm{O}_{4} \times 2 \mathrm{H}_{2} \mathrm{O}\right)$, phytic acid, potassium thiocyanate $(\mathrm{KSCN})$ standard and trichloroacetic acid (TCA) were purchased from Sigma-Aldrich (Poland). Acetone, sulfuric acid (96\%), nitric acid (65\%), potassium manganate(VII), ferric chloride $\left(\mathrm{FeCl}_{3} \times 6 \mathrm{H}_{2} \mathrm{O}\right)$, EDTA, sodium hydroxide, sodium sulfate(VI), sulfosalicylic acid were supplied from Chempur (Poland). Every one of the standards and reagent were at analytical grade. Deionized water (conductivity $<0.05 \mu \mathrm{S}$ ) was used to prepare solutions. 


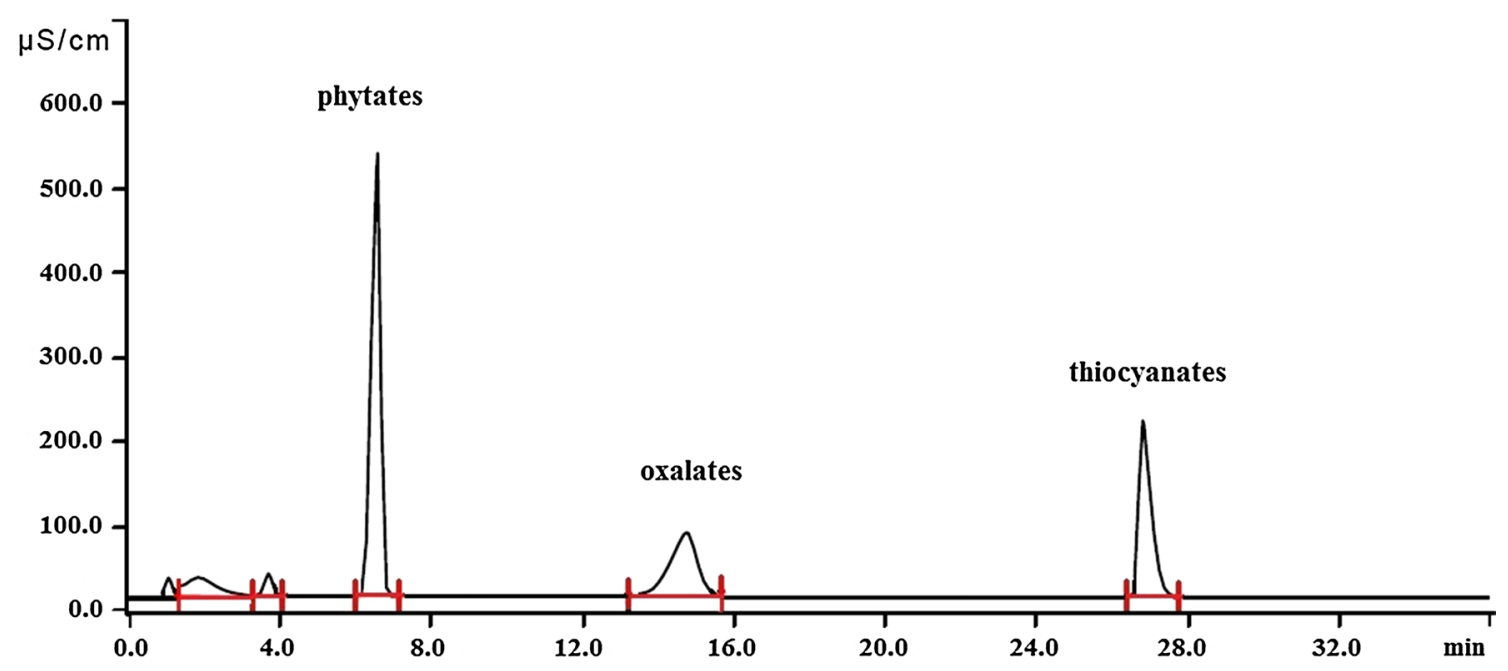

Fig. 1 Typical chromatograms of phytates, oxalates and thiocyanates standards

\section{Apparatus}

Ion chromatograph 883 Basic IC plus (Metrohm, Switzerland) was used for simultaneous determination of watersoluble oxalates, phytates and thiocyanates. UV-Vis spectra were recorded on a UV-Vis HELIOS $\alpha$ spectrophotometer (Unicam, Cambridge, UK) in 1-cm quartz cell.

\section{Ion chromatography}

For the qualitative and quantitative analysis of studied anions $\left(\mathrm{C}_{2} \mathrm{O}_{4}{ }^{2-}, \mathrm{SCN}^{-}\right.$, phytates), ion chromatography method with a conductivity detector was used. Anion exchange column Metrosep A Supp 4-250/4.0, where polyvinyl alcohol quaternary amine was supplied in the solid phase. Column temperature was set at $25{ }^{\circ} \mathrm{C}$. Isocratic conditions with $1.8 \mathrm{mM} \mathrm{Na}_{2} \mathrm{CO}_{3}$ and $1.7 \mathrm{mM} \mathrm{NaHCO}_{3}$ as mobile phase was adapted to resolution of a anti-nutritional substances. The injection volume was $20 \mu \mathrm{L}$, whereas total flow rate was $1 \mathrm{~mL} \mathrm{~min}{ }^{-1}$. Peaks were identified by retention time and by spiking extracts with standards of analyzed standards (especially in water-soluble oxalates and thiocyanates). Typical chromatograms for the separation of a anti-nutritional standards are shown in Fig. 1.

The phytic acid calibration range was 0.10 $5.00 \mathrm{mg} \mathrm{mL}{ }^{-1}$, resulting in the calibration curves $y=$ $(6.41 \pm 0.106) x-(0.94 \pm 0.25),\left(R^{2}=0.9996\right.$, RSDslope $=2.71 \%, \mathrm{DL}=0.11 \mathrm{mg} \mathrm{mL}^{-1}, \mathrm{QL}=0.37 \mathrm{mg} \mathrm{mL}^{-1}$, $n=5$ ). The accuracy of the method was determined by adding appropriate amounts of standard solutions and calculating the mean recoveries $97.15 \pm 0.12 \%$.

Determination of water-soluble oxalates and thiocyanates in the Asian plants was obtained by the standard addition method. The standard solutions $(0.5,1.0,1.5,2.5$ and $3.0 \mathrm{~mL}$ ) were added to sample and calibration curves recorded (five samples for each of the 20 extracts).

\section{Extraction procedure: determination of anti-nutritional substances by IC}

The grounded, dried samples $(1.50 \pm 0.01 \mathrm{~g})$ of studied plant samples were extracted three times with $25 \mathrm{~mL}$ of deionized water by extraction in water bath (at $30{ }^{\circ} \mathrm{C}$ for $60 \mathrm{~min})$. Next extracts were centrifuged $(4500 \mathrm{rpm}$, $15 \mathrm{~min})$. The supernatant solution was filtered, and then, the extract was taken directly to the appropriate chromatographic analysis. Before the injection, extracts were filtered through a MCE syringe filter (diameter $25 \mathrm{~mm}$, pore size $0.45 \mu \mathrm{m})$.

\section{Determination of water-soluble oxalates by titration}

Modified titration method of determination of water-soluble oxalates was as previously described by Baker [7]. The grounded, dried samples $(3.00 \pm 0.01 \mathrm{~g})$ of studied plant samples were extracted by $50 \mathrm{~mL}$ boiling distilled water and then stirred for $15 \mathrm{~min}$ on a shaker. To the centrifuge tube, $3.0 \mathrm{~mL}$ supernatant solution was collected; $1.75 \mathrm{~mL}$ of $5 \%$ solution of calcium chloride and $1.75 \mathrm{~mL}$ of acetone were added and then were mixed and placed in the refrigerator. After $30 \mathrm{~min}$, the resulting precipitate was centrifuged, next the supernatant was decanted, and the precipitate was quantitatively transferred to a conical flask with $10 \%$ sulfuric(VI) acid solution and dissolved $\left(90^{\circ} \mathrm{C}\right)$. After dissolving, hot solution was titrated $0.0224 \mathrm{M}$ solution of $\mathrm{KMnO}_{4}$ to obtain a pink color continuing for about $1 \mathrm{~min}$. 


\section{Determination of thiocyanates by spectrophotometric method}

The procedure of thiocyanate analysis based on a determination methodology described by Hovinen et al. [14] and van Staden and Botha [15]. The basis of spectrophotometric method is the reaction of $\mathrm{SCN}^{-}$with $\mathrm{Fe}^{3+}$. To prepare a standard curve in the range $1.0-10.0 \mu \mathrm{g} \mathrm{mL}^{-1}$, the appropriate volume of standard solution was collected in volumetric flasks (volume $10 \mathrm{~mL}$ ) and then $5 \mathrm{~mL}$ of $0.4 \mathrm{M}$ solution of ferric chloride(III) in $2 \mathrm{MHCl}$ and $5 \%$ trichloroacetic acid solution were added. Absorbance was measured at $\lambda=470 \mathrm{~nm}$, in time no more than $5 \mathrm{~min}$ after the addition of a solution of iron(III). In the resulting, the calibration curves equation was obtained $y=(0.0682 \pm 0.0014) x$ $-(0.0037 \pm 0.0087),\left(R^{2}=0.9994, \mathrm{RSD}_{\text {slope }}=1.47 \%\right.$, $\mathrm{DL}=0.24 \mu \mathrm{g} \mathrm{mL}^{-1}, \mathrm{QL}=0.81 \mu \mathrm{g} \mathrm{mL}^{-1}$, mean recoveries $97.73 \pm 0.12 \%$ ) for five repeat measurements.

The grounded, dried samples (2.00-2.50 $\pm 0.01 \mathrm{~g})$ of studied plant samples were extracted by $20 \mathrm{~mL}$ of $5 \%$ TCA solution and shaken for $15 \mathrm{~min}$. Then, the precipitate was centrifuged and filtered (filtrate was used in the analysis). Next, blank solution (filtrate $+2 \mathrm{~mL}$ distilled water), specific sample solution (filtrate $+2 \mathrm{~mL}$ solution of ferric(III) chloride in $2 \mathrm{M} \mathrm{HCl}$ ) and reagent test $[2 \mathrm{~mL}$ of distilled water and $2 \mathrm{~mL}$ solution of ferric chloride (III) in $2 \mathrm{M} \mathrm{HCl}$ ] were prepared. On the basis of the average absorbance measured at $\lambda=470 \mathrm{~nm}$ for specific sample solution $\left(A_{\mathrm{S}}\right)$, blank solution $\left(A_{\mathrm{B}}\right)$ and reagent test $\left(A_{\mathrm{R}}\right)$ concentration of $\mathrm{SCN}^{-}$were determined in the samples using the dependence: $A_{\mathrm{SCN}^{-}}=A_{\mathrm{S}}-A_{\mathrm{B}}-A_{\mathrm{R}}$. The absorbance of the reagent test was $0.266 \pm 0.009$, whereas absorbances for specific sample and blank solutions were characteristic of the individual plant extracts.

\section{Determination of phytic acid by titration}

Modified method of determination of phytic acid content was performed by the method described by García-Estepa et al. [22] and Febles et al. [21], which was used to determine the amount of phytic acid in flours and cereal products. The grounded, dried samples $(3.00 \pm 0.01 \mathrm{~g})$ of studied plant samples were extracted $20 \mathrm{~mL}$ of $5 \%$ solution of $\mathrm{Na}_{2} \mathrm{SO}_{4}$ in $0.4 \mathrm{M} \mathrm{HCl}$, shaken for $60 \mathrm{~min}$ and then centrifuged for $15 \mathrm{~min}$. After centrifugation, the whole extract was transferred to a conical flask and $20 \mathrm{~mL} 5 \% \mathrm{Na}_{2} \mathrm{SO}_{4}$ in $0.4 \mathrm{M} \mathrm{HCl}, 20 \mathrm{~mL} \mathrm{Fe}(\mathrm{III})$ solution, $20 \mathrm{~mL} 20 \%$ solution of sulfosalicylic acid were added and the content was heated for $15 \mathrm{~min}$ in a water bath $\left(80^{\circ} \mathrm{C}\right)$. After the precipitation iron phytate on a cold and centrifugation, supernatant was diluted with deionized water. The $\mathrm{pH}$ was adjusted with $1 \mathrm{M} \mathrm{NaOH}$ to 2.5 and then heated to $70{ }^{\circ} \mathrm{C}$ and titrated with $0.01 \mathrm{M}$ EDTA solution to pale yellow.

\section{Statistical analysis}

The mean differences were considered significant at the $p<0.05$ level. One-way ANOVA, followed by Duncan test, was preformed to analyze the significant differences between data $(p<0.05)$ for oxalates, phytates, thiocyanates in the plant samples using Statistica (Windows software package, version 10.0 PL).

\section{Results and discussion}

Obtained results for determination of oxalates, phytates and thiocyanates are given in Table 1, whereas exemplary chromatogram registered for Bupleurum sinensis is shown in Fig. 2.

Soluble oxalates, thiocyanates and phytic acid in the tested plant materials were determined by ion chromatography method using modified procedure. The performed analysis was based on a comparison of retention times for the standard and the samples and the standard addition. In some cases, the resulting retention times differ by a few percent; however, the greatest differences were observed in the case of phytic acid. Phytic acid molecule has 12 protons removable, so that it can create 12 different anions (from mono- to dodeca-). Depending on the structure of their anions, retention time may be varied due to the different strength of binding to the stationary phase. Moreover, phytic acid anions exhibit greater mass than the phosphate anion $\mathrm{PO}_{4}{ }^{3-}$; hence, inorganic phosphates do not interfere in determination of phytic acid by IC method.

Results, besides the phytates, were analyzed by ANOVA with Duncan's test, $p<0.05$ (Table 1). Concentration of phytates was expressed in $\mathrm{mg} / 100 \mathrm{~g}$ d.m. (IC) but \% $(\mathrm{g} / 100 \mathrm{~g})$ for titration method; hence, comparison of statistically differences was impossible. We used different letters $(\mathrm{a}, \mathrm{b})$ within the same column only for AP samples, but in the line letters $\mathrm{x}$ and $\mathrm{y}$, which indicate significant differences between methods. Comparing the results for each anti-nutritional component, should be noted that in all cases statistically significant difference were observed. Only the oxalates content for Apl-B and APl-S (in the same methods, letters ${ }^{\mathrm{b}}$ ) and for thiocyanates analysis by both methods in AS and CL we observed statistically similar results. Based on the F-Snedecor and Student's $t$ tests, it should be noted that the method IC characterized a higher precision and accuracy with respect to the reference methods (titration and spectrophotometric).

Analysis of the results given in Table 1, we observed that for the studied Asian plants, the highest oxalate ion concentration in relation to the thiocyanates and phytic acid. Plant materials contain the least phytates. In every case, the relative standard deviation $(\mathrm{RSD})$ was $<7 \%$. The content 
Table 1 Anti-nutritional substances content in Asiatic plants

\begin{tabular}{|c|c|c|c|c|c|c|}
\hline & \multicolumn{6}{|c|}{ Anti-nutritional substances } \\
\hline & \multicolumn{2}{|c|}{ Water-soluble oxalates } & \multicolumn{2}{|l|}{ Thiocyanates } & \multicolumn{2}{|l|}{ Phytates } \\
\hline & $\begin{array}{l}\mathrm{IC}(\mathrm{mg} / 100 \mathrm{~g} \mathrm{~d} . \mathrm{m} .) \\
n=3, p=0.05\end{array}$ & $\begin{array}{l}\text { Titration (mg/100 g d.m.) } \\
n=5, p=0.05\end{array}$ & $\begin{array}{l}\mathrm{IC}(\mathrm{mg} / 100 \mathrm{~g} \mathrm{s.m} .) \\
n=3, p=0.05\end{array}$ & $\begin{array}{l}\mathrm{UV}-\mathrm{Vis}(\mathrm{mg} / 100 \mathrm{~g} \text { d.m.) } \\
n=5, p=0.05\end{array}$ & $\begin{array}{l}\mathrm{IC}(\mathrm{mg} / 100 \mathrm{~g} \mathrm{~d} . \mathrm{m} .) \\
n=3, p=0.05\end{array}$ & $\begin{array}{l}\text { Titration }(\%) \\
n=5, p=0.05\end{array}$ \\
\hline Аa & $20.44 \pm 0.27^{x}$ & $23.71 \pm 0.27^{y}$ & $5.51 \pm 0.22^{y}$ & $0.03 \pm 0.00^{\mathrm{x}}$ & $13.52 \pm 0.19$ & n.d. \\
\hline Amla & $52.05 \pm 1.02^{\mathrm{x}}$ & $58.40 \pm 1.39^{y}$ & $26.22 \pm 1.13^{\mathrm{x}}$ & $29.31 \pm 1.77^{y}$ & $16.13 \pm 0.35$ & n.d. \\
\hline APr-S & $50.26 \pm 1.52^{\mathrm{a}, \mathrm{x}}$ & $61.21 \pm 1.67^{\mathrm{a}, \mathrm{y}}$ & $21.41 \pm 0.87^{\mathrm{x}}$ & $24.26 \pm 1.01^{\mathrm{y}}$ & $10.22 \pm 0.25$ & n.d. \\
\hline APl-S & $110.44 \pm 1.97^{\mathrm{b}, \mathrm{x}}$ & $124.62 \pm 2.51^{\mathrm{b}, \mathrm{y}}$ & $25.83 \pm 1.04^{\mathrm{x}}$ & $30.47 \pm 0.92^{\mathrm{y}}$ & $11.98 \pm 0.18$ & n.d. \\
\hline APl-B & $111.93 \pm 2.35^{\mathrm{b}, \mathrm{x}}$ & $125.22 \pm 2.75^{\mathrm{b}, \mathrm{y}}$ & $27.41 \pm 1.13^{x}$ & $32.75 \pm 1.69^{y}$ & $12.17 \pm 0.19$ & n.d. \\
\hline AS & $14.55 \pm 0.62^{x}$ & $17.82 \pm 0.62^{y}$ & $5.65 \pm 0.33^{\mathrm{x}}$ & $5.76 \pm 0.88^{\mathrm{x}}$ & $1.84 \pm 0.13$ & n.d. \\
\hline BM & $41.13 \pm 0.99^{x}$ & $48.07 \pm 0.53^{\mathrm{y}}$ & $16.52 \pm 0.96^{\mathrm{x}}$ & $20.09 \pm 1.31^{\mathrm{y}}$ & $3.03 \pm 0.11$ & n.d. \\
\hline BS & $16.53 \pm 0.47^{x}$ & $19.12 \pm 0.86^{\mathrm{y}}$ & $4.59 \pm 0.21^{\mathrm{x}}$ & $5.32 \pm 0.99^{y}$ & $2.77 \pm 0.31$ & n.d. \\
\hline $\mathrm{CA}$ & $28.85 \pm 0.53^{x}$ & $36.94 \pm 1.11^{\mathrm{y}}$ & $11.27 \pm 0.74^{\mathrm{x}}$ & $13.25 \pm 1.49^{\mathrm{y}}$ & $4.23 \pm 0.24$ & n.d. \\
\hline CL & n.d. & n.d. & $0.94 \pm 0.11^{\mathrm{x}}$ & $0.96 \pm 0.13^{\mathrm{x}}$ & $0.42 \pm 0.04$ & n.d. \\
\hline FoTi & $0.38 \pm 0.03^{\mathrm{x}}$ & $0.42 \pm 0.03^{\mathrm{y}}$ & $1.44 \pm 0.09$ & n.d. & $0.94 \pm 0.03$ & $0.67 \pm 0.04$ \\
\hline GC & $121.41 \pm 2.15^{\mathrm{x}}$ & $137.52 \pm 3.22^{y}$ & n.d. & $14.15 \pm 0.44$ & $2.45 \pm 0.12$ & $0.16 \pm 0.03$ \\
\hline MP & $3.58 \pm 0.31^{\mathrm{x}}$ & $5.66 \pm 0.24^{\mathrm{y}}$ & $2.16 \pm 0.17^{\mathrm{x}}$ & $2.40 \pm 0.12^{\mathrm{y}}$ & $0.95 \pm 0.05$ & $1.61 \pm 0.11$ \\
\hline OS & $145.39 \pm 2.11^{x}$ & $153.22 \pm 1.35^{y}$ & $34.34 \pm 1.98^{x}$ & $38.21 \pm 2.22^{y}$ & $2.66 \pm 0.13$ & n.d. \\
\hline PG & $2.71 \pm 0.13^{\mathrm{x}}$ & $2.98 \pm 0.08^{y}$ & $4.02 \pm 0.24^{\mathrm{x}}$ & $5.33 \pm 0.56^{\mathrm{y}}$ & $1.47 \pm 0.11$ & $1.65 \pm 0.08$ \\
\hline PL & $11.23 \pm 0.43^{x}$ & $12.90 \pm 0.33^{y}$ & $5.50 \pm 0.31^{x}$ & $7.03 \pm 0.41^{\mathrm{y}}$ & $2.08 \pm 0.52$ & n.d. \\
\hline SM & $14.30 \pm 0.37^{\mathrm{x}}$ & $15.42 \pm 0.58^{\mathrm{y}}$ & $5.20 \pm 0.20^{\mathrm{x}}$ & $6.16 \pm 0.65^{y}$ & $1.54 \pm 0.06$ & n.d. \\
\hline SS-FL & $6.65 \pm 0.23^{x}$ & $7.72 \pm 0.31^{\mathrm{y}}$ & $2.85 \pm 0.13^{x}$ & $3.19 \pm 0.08^{y}$ & n.d. & n.d. \\
\hline SS-S & $6.11 \pm 0.22^{\mathrm{x}}$ & $6.89 \pm 0.18^{\mathrm{y}}$ & $3.56 \pm 0.42^{\mathrm{x}}$ & $4.04 \pm 0.11^{\mathrm{y}}$ & $0.35 \pm 0.03$ & n.d. \\
\hline TA & $32.52 \pm 0.72^{x}$ & $37.93 \pm 1.16^{\mathrm{y}}$ & $14.99 \pm 0.71^{x}$ & $16.54 \pm 0.84^{y}$ & $10.49 \pm 0.43$ & n.d. \\
\hline
\end{tabular}

n.d. not detected, different letters $(\mathrm{a}, \mathrm{b})$ within the same column for AP samples, and line ( $\mathrm{x}$ and $\mathrm{y}$ ) indicate significant differences (one-way ANOVA and Duncan test, $p<0.05$ ) between methods; d.m. dry mass

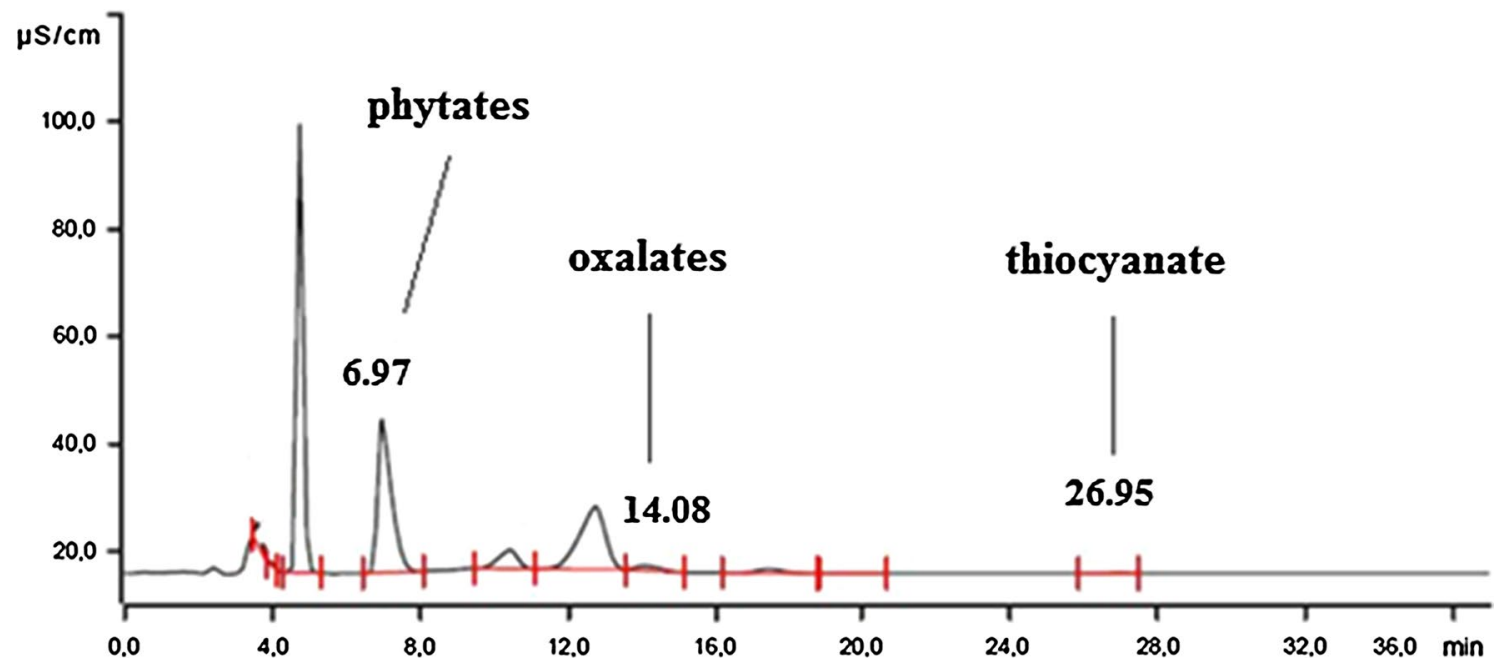

Fig. 2 Chromatogram of Bupleurum sinensis extract

of oxalate determined by titration was in the range of 0.42

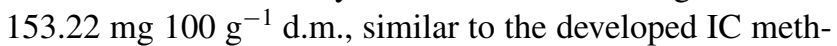
odology $0.38-145.39 \mathrm{mg} 100 \mathrm{~g}^{-1}$ d.m., respectively for
Foti and Ocimum sanctum. The obtained results differ significantly (ANOVA, followed by Duncan test) and may be due to the difference in the two oxalates extraction methods 
which was used or the difficulty in observing the titration endpoint. Only for CL oxalates were not detected. Taking into account the results, it can be concluded that for the leaves higher amounts of oxalic acid in relation to fruits and roots were obtained. For the roots, we observed the lowest values. Additionally, the molar ratio of $(\mathrm{COOH})_{2} / \mathrm{Ca}$ for the obtained average content was determined. In every case, this ratio does not exceed the value of 1.0 (the highest was for TA 0.56). Therefore, there is no scientific principle for the threat of excessive losses minerals caused by supplements, which contain studied plants from Asia.

Thiocyanate concentration was in the range 0.96$38.21 \mathrm{mg} 100 \mathrm{~g}^{-1}$ d.m. for Curcuma longa and Ocimum sanctum, respectively, which are analogy with the IC method 0.94-34.34 mg $100 \mathrm{~g}^{-1}$ d.m., but only for AS and CL samples we observed similarity in the concentration values. Thiocyanate ions were not detected in Garcinia cambogia.

Content of phytic acid $\left(0.42-16.13 \mathrm{mg} 100 \mathrm{~g}^{-1}\right.$ d.m. for the SS-S and Amla, respectively) determined by ion chromatography was the lowest in comparison with the thiocyanates and oxalates. In the SS-FL, phytic acid was not detected. Analyzing the results obtained for the titration (0.16-1.65 \% for GC and PG), we get the results much higher than in the method of the IC.

Al-Wahsh et al. [27] using an enzymatic method marked oxalates content in 50 various herbs used in medicine and ten fresh fruits. The results obtained by the authors are as follows: The content of soluble oxalates extracted in heat was in the range of 18-1452 mg $100 \mathrm{~g}^{-1}$ d.m. for Trigonella foenum graecum and Peganum harmala, while in the case of fruit content ranges from $0.30 \mathrm{mg} 100 \mathrm{~g}^{-1} \mathrm{~d} . \mathrm{m}$. for the peaches and $6.6 \mathrm{mg} 100 \mathrm{~g}^{-1}$ d.m.. for kiwi. In addition, high levels (>1000 mg $100 \mathrm{~g}^{-1}$ d.m.) of oxalates are commonly observed in tropical plants like taro and sesame seeds [27]. Adeniyi et al. [28] determined oxalates in selected Nigerian food samples (Solanum tuberosum L., Ipomea batatas L., Discorea alata, Dioscorea rotundata, Colocasia esculents L., Triticum vulgare, Soja hispida and Amarathus sp), resulting range from 20 to $92 \mathrm{mg}$ per $100 \mathrm{~g}$ of fresh weight sample. Oranges, bananas, peaches and pears have been previously reported to contain within the range of $2-10 \mathrm{mg}$ total oxalate $/ 100 \mathrm{~g}$ fresh weight [9]. Al-Wahsh et al. [27] obtained the higher concentration values in comparison with these presented in manuscript (0.38-145.39 mg $100 \mathrm{~g}^{-1}$ d.m.,), but Honov and Hesse [9], Adeniyi et al. [28] results were in the same concentration level. Researchers [29] determined glucosinolates in cabbage (68.6-238.8 $\mu \mathrm{mol} / 100 \mathrm{~g}$ fresh $\mathrm{wt}$ ), brussels (367$553 \mu \mathrm{mol} / 100 \mathrm{~g}$ fresh $\mathrm{wt})$, collards $(220.4 \mu \mathrm{mol} / 100 \mathrm{~g}$ fresh $\mathrm{wt})$, broccoli (161.9-248.4 $\mu \mathrm{mol} / 100 \mathrm{~g}$ fresh wt). The average levels of phytic acid in the infant food ( $363 \mathrm{mg} / 100 \mathrm{~g}$ ) [26], in cereal grains, legumes and feeds $(<0.08 \%)[23]$ were higher than presented in this study.
It is difficult to compare our results with others, because of using different materials, different analytical methods, different preparation of samples. Additionally, analyzing these obtained results and the literature data, we can concluded that the content of oxalates, thiocyanates and phytates in teas, vegetables, fruits or plant material is varied and depends on the genetic, environmental and location factors, e.g., difference cultivar, species, maturity and morphological parts of the plant, region of origin, harvest period, manner and processing technology, agronomic conditions as well as the soil condition or use of fertilizers.

Unfortunately, the obtained results of the determination of individual anti-nutritional substances cannot be compared with the results of other scientists, because in the literature there were no data about analyzed substances in studied Asiatic plant materials. Therefore, the subjects related to the search for methods for the determination of phytates, oxalates, and thiocyanates in plants and food supplements deserve special attention. An important aspect of this is the fact that the supplements should enrich and supplement the human diet with ingredients which have a positive impact on health and body, and not be a source of anti-nutritional substances, which have a completely different effect.

The proposed method of ion chromatography for the simultaneous determination of phytates, oxalates, and thiocyanates in the plant matrix seems to be appropriate, and the proposed methodology can be competitive in relation to conventional methods. An important advantage of the developed methodology for determining is short analysis time (15 min), during which we receive information about the contents of the three tested ingredients. Moreover, samples preparation procedure is not complicated and time consuming. In summary health aspect, it was found that the tested plant materials do not constitute a serious threat to human health when people used only commercially available dietary supplements. However, due to the content of soluble oxalates and other studied substances in food, intake of anti-nutritional components should be controlled and limited, particularly for those people with healthy problem (e.g., kidney dysfunction or the tendency to nephrolithiasis). Additionally, our results may be useful in the planning of rational nutrition and production of dietary supplements.

Acknowledgments Project was funded by the National Science Centre granted on the basis of the decision number DEC-2012/07/N/ NZ9/00965.

\section{Compliance with ethical standards}

Conflict of interest Anna Filipiak-Szok has received research grant from National Science Centre (decision number DEC-2012/07/N/ NZ9/00965). 
Anna Filipiak-Szok declares also that research has been founded from NCU funds (task No. 252).

Marzanna Kurzawa declares that research has been founded from NCU funds (task No. 252).

Edward Szłyk declares that research has been founded from NCU funds (task No. 252).

Compliance with ethics requirements This article does not contain any studies with human or animal subjects.

Open Access This article is distributed under the terms of the Creative Commons Attribution 4.0 International License (http://creativecommons.org/licenses/by/4.0/), which permits unrestricted use, distribution, and reproduction in any medium, provided you give appropriate credit to the original author(s) and the source, provide a link to the Creative Commons license, and indicate if changes were made.

\section{References}

1. Deshpande SS (2002) Handbook of food toxicology. Marcel Dekker Inc, USA

2. Massey LK (2007) Food oxalate: factors affecting measurement, biological variation, and bioavailability. J Am Diet Assoc 107(7):1191-1194

3. Robertson WG (2004) Role of dietary intake and intestinal absorption of oxalate in calcium stone formation. Nephron Physiol 98:64-71

4. Gasińska A, Gajewska D (2007) Tea and coffee as the main sources of oxalate in diets of patients with kidney oxalate stones. Annu PZH 58:61-67

5. Brauer VFH, Below H, Kramer A, Führer D, Paschke R (2006) The role of thiocyanate in the etiology of goiter in an industrial metropolitan area. Eur J Endocrinol 154:229-235

6. Oatway L, Vasanthan T, Helm JH (2001) Phytic acid. Food Rev Int 17:419-431

7. Baker CJL (1952) The determination of oxalates in fresh plant material. Analyst 77:340-344

8. Charrier MS, Savage GP, Vanhanen L (2002) Oxalate content and calcium binding capacity of tea and herbal teas. Asia Pac J Clin Nutr 11(4):298-301

9. Honow R, Hesse A (2002) Comparison of extraction methods for the determination of soluble and total oxalate in foods by HPLCenzyme-reactor. Food Chem 78:511-521

10. Merusi C, Corradini C, Cavazza A, Borromei C, Salvadeo P (2010) Determination of nitrates, nitrites and oxalates in food products by capillary electrophoresis with $\mathrm{pH}$-dependent electroosmotic flow reversal. Food Chem 120:615-620

11. Geng X, Zhang S, Wang Q, Zhao Z (2008) Determination of organic acids in the presence of inorganic anions by ion chromatography with suppressed conductivity detection. J Chromatogr A $1192: 187-190$
12. Perez-Ruiz T, Martinem-Lozano C, Tomas V, Fenoli J (2005) Chemiluminescent determination of oxalate based on its enhancing effect on the oxidation of methyl red by dichromate. Anal Chim Acta 552(1-2):147-151

13. Kim YE, Hong SH, Kim JW, Lee JY (2006) Evaluation of Fourier transform near-infrared spectrometer for determination of oxalate in standard urinary solution. J Prev Med Public Health 39(2): $165-170$

14. Hovinen J, Lahti M, Vilpo J (1999) Spectrophotometric determination of thiocyanate in human saliva. J Chem Educ 76(9):1281-1288

15. van Staden JF, Botha A (2000) Spectrophotometric determination of thiocyanate by sequential injection analysis. Anal Chim Acta 403:279-286

16. Gong B, Gong G (1999) Fluorimetric method for the determination of thiocyanate with $2^{\prime}, 7^{\prime}$-dichlorofuorescein and iodine. Anal Chim Acta 394:171-175

17. Vinca CM, Spiridon-Bizerea O, Vlascici D (2006) Comparative study determination of thiocyanate from biological liquids. Ser Chem 15(1):87-90

18. Ma YI, Li M, Yu H, Li RS (2013) Fast analysis of thiocyanate by ion-pair chromatography with direct conductivity detection on a monolithic column. Chin Chem Lett 24:1067-1069

19. Glatz Z, Nováková S, Šterrbova H (2001) Analysis of thiocyanate in biological fluids by capillary zone electrophoresis. J Chromatogr A 916:273-277

20. Bjergegaard C, Moiler P, Sorensen H (1995) Determination of thiocyanate, iodide, nitrate and nitrite in biological samples by micellar electrokinetic capillary chromatography. J Chromatogr A 717:409-414

21. Febles CI, Arias A, Hardisson A, Rodríguez-Alvarez C, Sierra A (2002) Phytic acid level in wheat flours. J Cereal Sci 36:19-23

22. García-Estepa RM, Guerra-Hernández E, García-Villanova B (1999) Phytic acid content in milled cereal products and breads. Food Res Int 32:217-221

23. Blatny P, Kvasnicka F, Kendler E (1995) Determination of phytic acid in cereal grains, legumes, and feeds by capillary isotachophoresis. J Agric Food Chem 43:129-133

24. Chen Q (2004) Determination of phytic acid and inositol pentakisphosphates in foods by high-performance ion chromatography. J Agric Food Chem 52:4604-4613

25. Park HR, Ahn HJ, Kim SH, Lee CH, Byun MW, Lee GW (2006) Determination of the phytic acid levels in infant foods using different analytical methods. Food Control 17:727-732

26. Chen Y, Chen J, Luo Z, Ma K, Chen X (2009) Synchronous fluorescence analysis of phytate in food. Microchim Acta 164:35-40

27. Al-Wahsh IA, Wu Y, Liebman M (2012) A comparison of two extraction methods for food oxalate assessment. J Food Res 1(2):233-239

28. Adeniyi SA, Orjiekwe CL, Ehiagbonare JE (2009) Determination of alkaloids and oxalates in some selected food samples in Nigeria. Afr J Biotechnol 8(1):110-112

29. Janick J (ed) (1997) Horticultural reviews, vol 19. Wiley, New York 